\title{
Red de vigilancia de resistencia antimicrobiana PRONARES. Informe primer semestre 2001
}

\author{
OLIVIA TRUCCO A.*, VALERIA PRADO J.*, TM CLAUDIA DURÁN T.* y GRUPO PRONARES**
}

\author{
PRONARES ANTIMICROBIAL SURVEILLANCE NETWORK ON \\ ANTIMICROBIAL AGENTS RESISTANCE: REPORT OF THE FIRST \\ SEMESTER 2001
}

\begin{abstract}
During the last years we have seen are emerging antimicrobial agents resistance that compromise more strains, new species and new mechanisms. In November 1997 we iniciated a network of antimicrobial surveillance named PRONARES in differents hospitals that working with a unique protocol (20 strains by month by syndrome) and using a computational software WHONET surveys the resistance in Chile. The results obtained during the first semester of 2001 shows the susceptibility pattern of 5.251 strains isolated from different clinical syndromes. In urinary tract infections $\boldsymbol{E}$. coli (1.088 strains) were very susceptible to all the antibiotics tested, Klebsiella spp (1.000 strains) were more resistant. In Enterococcus we observed $30 \%$ of ciprofloxacin resistance and 2\% of nitrofurantoin resistance. Among 899 invasive strains, S. aureus (655 strains) presented a high methicillin resistance level (40\%) more than 20\% observed in skin and soft tissue infections. Shigella spp (137) presented $80 \%$ of ampicillin resistance and $32 \%$ to chloramphenicol. Ciprofloxacin and furazolidone had better activity. Comparing nosocomial and community strains, the higher pattern of resistance was observed in nosocomial strains. It is very important to maintain the surveillance network to prescribe the appropriate antimicrobial and to avoid the increase of resistance.
\end{abstract}

Key words: Surveillance, In vitro susceptibility.

\section{INTRODUCCIÓN}

La resistencia antimicrobiana aparece junto a la introducción de los antimicrobianos para combatir las enfermedades infecciosas. En el transcurso de los años, el uso aumentado y masivo de antimicrobianos en el hombre, animales, peces y en la agricultura, ha transformado este fenómeno en un problema creciente, que involucra cada día mayor número de cepas, nuevas especies y nuevos mecanismos. El estudio del comportamiento de las bacterias fren-

\footnotetext{
* Instituciones participantes en PRONARES:

Hospitales Exequiel Gonzalez Cortés, Felix Bulnes, San Juan de Dios, San José, Sótero Del Río, Barros Luco Trudeau. Iquique, Gustavo Fricke de Viña Del Mar, Carlos Van Buren de Valparaíso, Regional de Concepción, Osorno. Nómina de profesionales en página S148.
} 
te a los antimicrobianos in vitro, se hace hoy cada vez más importante ya que somos incapaces de predecir la respuesta que ellas tendrán frente al antimicrobiano que queremos indicar. ${ }^{1}$

Las bacterias son particularmente eficientes en aumentar los efectos de la resistencia, no sólo por su habilidad de multiplicarse rápidamente sino también por su capacidad de transferir genes de resistencia a otras cepas o especies. Bacterias resistentes son capaces de diseminarse fácilmente entre las personas, y particularmente, en ambientes donde el uso elevado de antimicrobianos y la presencia de pacientes debilitados y susceptibles juntos (hospitales), hacen que la diseminación sea un fenómeno común. El enorme aumento de los viajes internacionales expone a los individuos a cepas resistentes de otras regiones y así, la diseminación de la resistencia se transforma en un problema mundial. ${ }^{2}$

El aumento creciente de resistencia en el extranjero como en nuestro medio, hace que la vigilancia de la resistencia antimicrobiana sea un pilar fundamental para orientar el manejo de los pacientes. ${ }^{3}$

Como las bacterias tienen múltiples posibilidades de resistir la acción de los antimicrobianos y se han descrito elevados niveles de resistencia en patógenos prevalentes, hoy es dificil elegir el tratamiento empírico adecuado para manejar numerosas enfermedades infecciosas. Será fundamental contar con la información microbiológica actualizada, que sirva de base para recomendar la mejor alternativa de entre las múltiples opciones con que contamos hoy.

Por ello nos propusimos desarrollar una red de laboratorios, que trabajando un protocolo común y utilizando un programa computacional WHONET (diseñado para vigilancia), nos permitiera detectar y monitorear el problema de la resistencia bacteriana en Chile. ${ }^{4}$ Este programa de vigilancia, iniciado desde fines del año 1997, llamado PRONARES (Programa Nacional de Resistencia), nos ha permitido obtener información de los problemas de resistencia en un número importante de cepas, de diferentes territorios de nuestro país. En esta oportunidad comunicamos el comportamiento de los agentes durante el primer semestre del año en curso. Un consolidado con la información de los tres años de vigilancia será publicado a la brevedad.

\section{MATERIAL Y MÉTODOS}

La red de vigilancia PRONARES se implementó en nuestro país en noviembre de 1997, desarrollando un protocolo común de vigilancia de resistencia antimicrobiana en patógenos prevalentes, agrupados por síndromes clínicos (infecciones invasoras, urinarias, de piel y tejidos blandos, entéricas y respiratorias). Durante el primer semestre del presente año han participado en esta vigilancia 11 centros de diferentes regiones del país: Iquique, Valparaíso, Viña del Mar, Concepción, Osorno y seis hospitales de la Región Metropolitana (Exequiel González Cortés, Félix Bulnes, San Juan de Dios, San José, Sótero Del Río y Barros Luco Trudeau).

\section{Sistema de vigilancia}

Cada centro envía los resultados del estudio de susceptibilidad antimicrobiana de 20 cepas aisladas por mes, de cada uno de los diferentes síndromes clínicos, (una cepa por paciente). El estudio de susceptibilidad in vitro realizado localmente mediante el método de difusión en agar con sensidiscos (técnica de Kirby-Bauer), se sujeta a las recomendaciones del NCCLS. En cada cepa estudiada se mide el halo de inhibición frente a antimicrobianos predeterminados (protocolo según patógeno y síndrome clínico $^{5}$ : ampicilina, ampicilina/sulbactam, cefazolina, cefalotina, cefuroxima, ceftriaxona, ceftazidima, cefepime, aztreonam, imipenem, gentamicina, amikacina, ciprofloxacina, nitrofurantoína y cotrimoxazol (Abreviaturas en Tabla 1).

El diámetro de los halos de inhibición del crecimiento (en milímetros) se registra en formularios ad hoc, que son enviados mensualmente a la Unidad de Microbiología Oriente de la Facultad de Medicina de la Universidad de Chile, donde son ingresados al programa computacional WHONET. Hoy cinco hospitales ingresan directamente sus datos en el programa WHONET y envían diskettes con la información.

Las cepas estudiadas son clasificadas como susceptibles, de susceptibilidad intermedia 
Tabla 1. Abreviaturas de antimicrobianos

\begin{tabular}{|c|c|}
\hline $\begin{array}{l}\text { - } \mathrm{AMP} \\
\text { - } \mathrm{CZO} \\
\text { - } \mathrm{CXM} \\
\text { - } \mathrm{CRO} \\
\text { - } \mathrm{CIP} \\
\text { - } \mathrm{NIT} \\
\text { - } \mathrm{GEN} \\
\text { - } \mathrm{AMK} \\
\text { - } \mathrm{CAZ} \\
\text { - SAM } \\
\text { - } \text { CSL } \\
\text { - FEP } \\
\text { - OXA } \\
\text { - } \mathrm{VAN} \\
\text { - IMP }\end{array}$ & $\begin{array}{l}\text { - Ampicilina } \\
\text { - Cefazolina } \\
\text { - Cefuroxima } \\
\text { - Ceftriaxona } \\
\text { - Ciprofloxacina } \\
\text { - Nitrofurantoína } \\
\text { - Gentamicina } \\
\text { - Amikacina } \\
\text { - Ceftazidima } \\
\text { - Ampicilina/sulbactam } \\
\text { - Cefoperazona/sulbactam } \\
\text { - Cefepime } \\
\text { - Oxacilina } \\
\text { - Vancomicina } \\
\text { - Imipenem }\end{array}$ \\
\hline
\end{tabular}

o resistentes según normas del NCCLS 2000, cuyos parámetros están incluidos en el programa WHONET. Los informes de la resistencia, son remitidos a cada laboratorio participante en forma periódica, mediante informes trimestrales acumulativos, para su uso institucional.

\section{Control de calidad}

La estandarización técnica y el control de calidad de los centros integrantes de la red se realizó al inicio, mediante distribución y análisis de un manual de procedimientos, visitas a los laboratorios participantes, distribución de cepas de referencia ATCC (Escherichia coli 25922, Staphylococcus aureus 29213, Pseudomonas aeruginosa 27853, Enterococcus faecalis
29212). Este control interno se mantiene hasta la fecha; en cada centro se estudian las cepas de referencia ATCC una vez por semana, siendo esta información analizada en el nivel central.

El ingreso de los halos de inhibición al programa WHONET de las cepas enviadas por cada laboratorio, tiene como criterio de validación el requisito de $80 \%$ de resultados dentro de los rangos aceptables para las cepas ATCC en cada centro (Gráfico 1).

\section{RESULTADOS}

Durante el primer semestre de este año se reportaron 5.251 cepas asociadas a diferentes síndromes clínicos. La frecuencia de especies reportadas se observa en el Gráfico 2, donde el agente más frecuente fue $E$. coli $(1.888$ cepas), seguido de $S$. aureus (1.082 cepas) y Klebsiella spp (502 cepas).

Del total de cepas reportadas, 2.068 provenían de infecciones del tracto urinario (ITU). La distribución de las especies en esta patología, se muestra en el Gráfico 3. El agente aislado con mayor frecuencia fue $E$. coli, el resto de agentes se presentó con mucha menor frecuencia.

La vigilancia de la resistencia en las enterobacterias más frecuentemente recuperadas en ITU, demuestra que E. coli en su mayoría ( $80 \%$ o más) fue sensible a cefazolina, cefuroxima, ceftriaxona, gentamicina, amika-

$\%$ de aceptabilidad

Gráfico 1. Control de calidad PRONARES. Aceptabilidad promedio de informes de estudio de sensibilidad. Período: enero-junio 2001. 
cina, ciprofloxacina y nitrofurantoína, mientras que $70 \%$ fue resistente a ampicilina. El perfil de resistencia en cepas de Klebsiella spp fue mayor al observado en E. coli, $100 \%$ de las cepas eran resistentes a ampicilina (resistencia natural intrínseca) y cerca de la mitad resistentes a cefazolina y nitrofurantoína, $30 \%$ de cepas fueron resistentes a cefalosporinas de tercera generación y ceftazidima, algo menor fue la resistencia a gentamicina y amikacina $(22 \%)$. $\mathrm{El}$ antimicrobiano más activo fue ciprofloxacina
(11\% de cepas resistentes). Las cepas de Proteus spp mostraron también elevado nivel de resistencia, específicamente a nitrofurantoína (90\%) (esta tan elevada resistencia deberá ser mejor evaluada) y a diferencia de las especies anteriores, también elevada resistencia a ciprofloxacina. No se indica la resistencia a cotrimoxazol entre las enterobacterias asociadas a ITU, ya que fueron estudiadas muy pocas cepas (Gráfico 4).

En el Gráfico 5, se observa la resistencia de

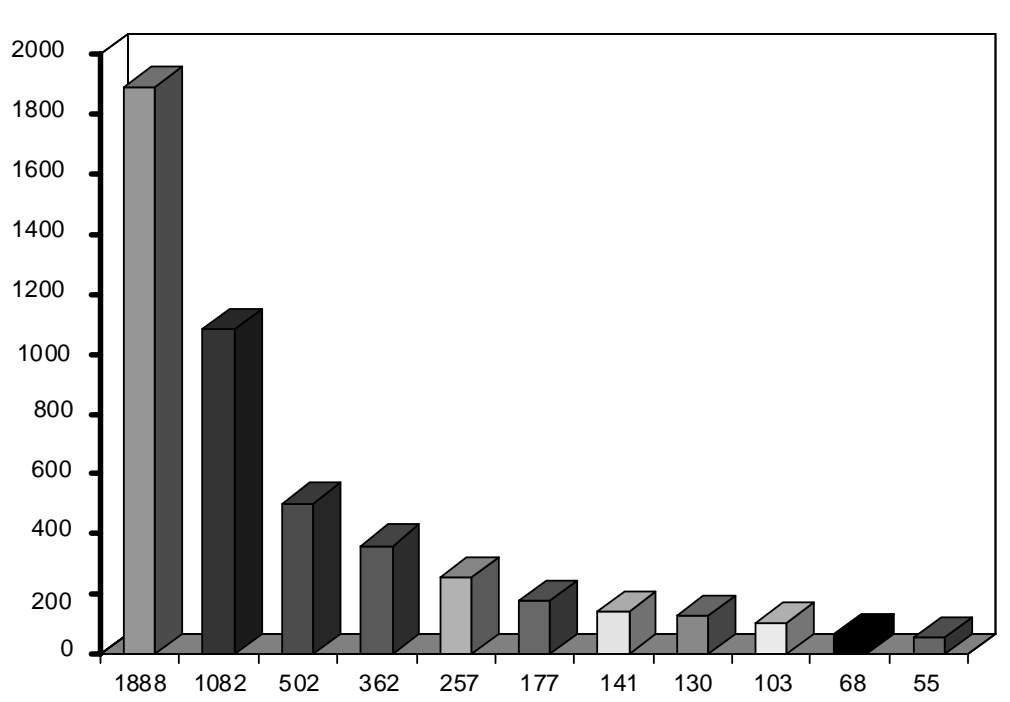

Escherichia coli

Staphylococcus.aureus

Klebsiella spp

Pseudomonas spp

Proteus spp

Acinetobacter spp

Shigella spp

Enterococcus spp

S.pneumoniae

Salmonella spp

Staphylococcus coagulasa (-)

Gráfico 2. Cepas procesadas por PRONARES, enero-junio 2001 (n: 5.251).

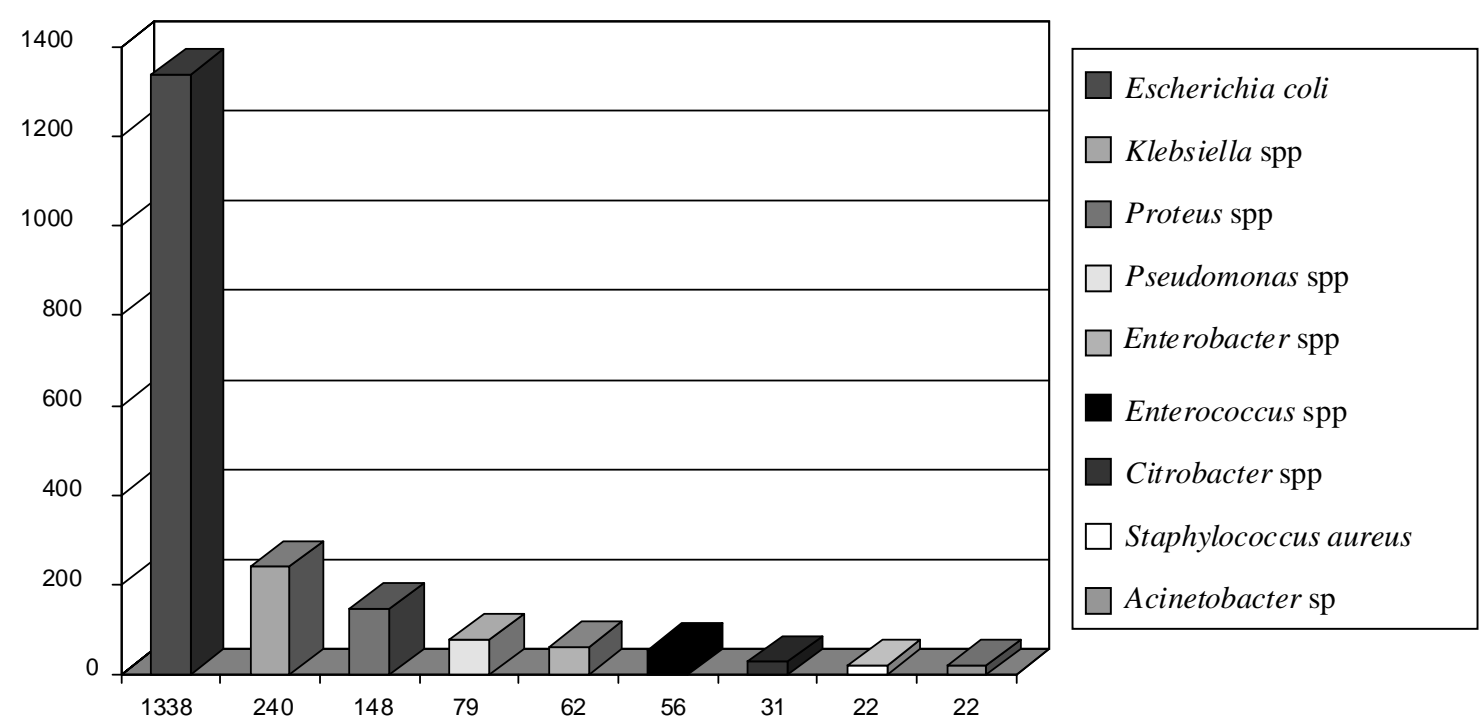

Gráfico 3. Infecciones del tracto urinario: Especies reportadas (n: 2.068). 
Enterococcus spp aislados de ITU, 10\% de cepas con resistencia a ampicilina, $30 \%$ a ciprofloxacina y $2 \%$ a nitrofurantoína; no hubo cepas resistentes a vancomicina.

En infecciones invasoras se reportaron 899 cepas (definidas como el aislamiento de la bacteria de un sitio estéril), cuya distribución por especie se observa en el Gráfico 6. Staphylococcus aureus, agente altamente prevalente, demostró un elevado perfil de resistencia a cloxacilina (40\%), incluidas cepas de adquisición nosocomial. Entre los bacilos no fermentadores, Pseudomonas spp fue menos resistente a los antimicrobianos estudiados que cepas de Acinetobacter spp, con menos de $30 \%$ de resistencia a ceftazidima, cefoperazona/ sulbactam, gentamicina, amikacina, imipenem y cefepime. Acinetobacter sp en cambio, demostró sobre $50 \%$ de resistencia a la mayoría de los antimicrobianos, con excepción de ampicilina/sulbactam (30\%), imipenem (10\%) y cefepime (20\%) (Gráfico 7).

Entre las enterobacterias invasoras, Klebsiella spp demostró tener un perfil de resistencia mucho más elevado que E. coli, con más del doble del porcentaje de resistencia

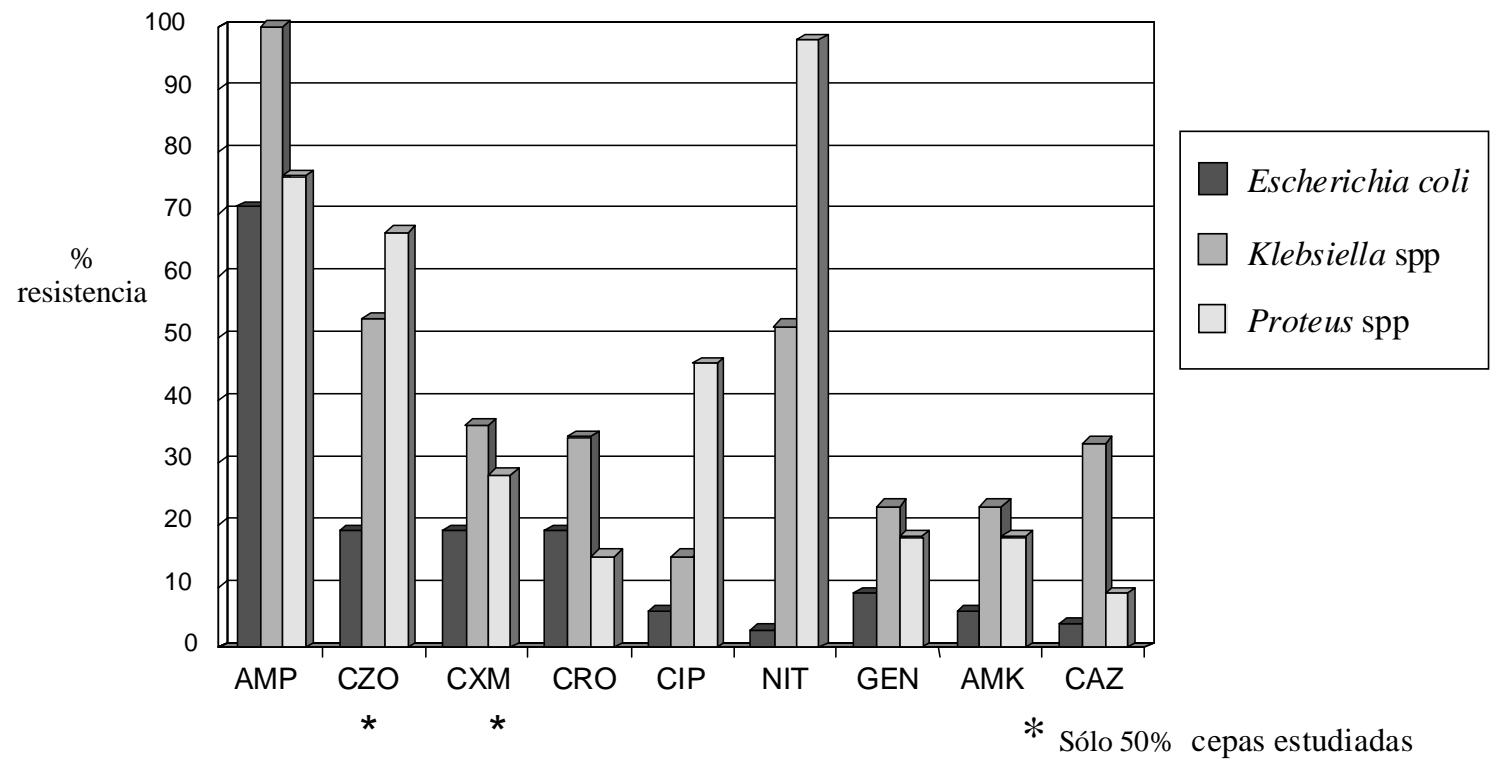

Gráfico 4. Resistencia antimicrobiana de enterobacterias procedentes de infecciones del tracto urinario.

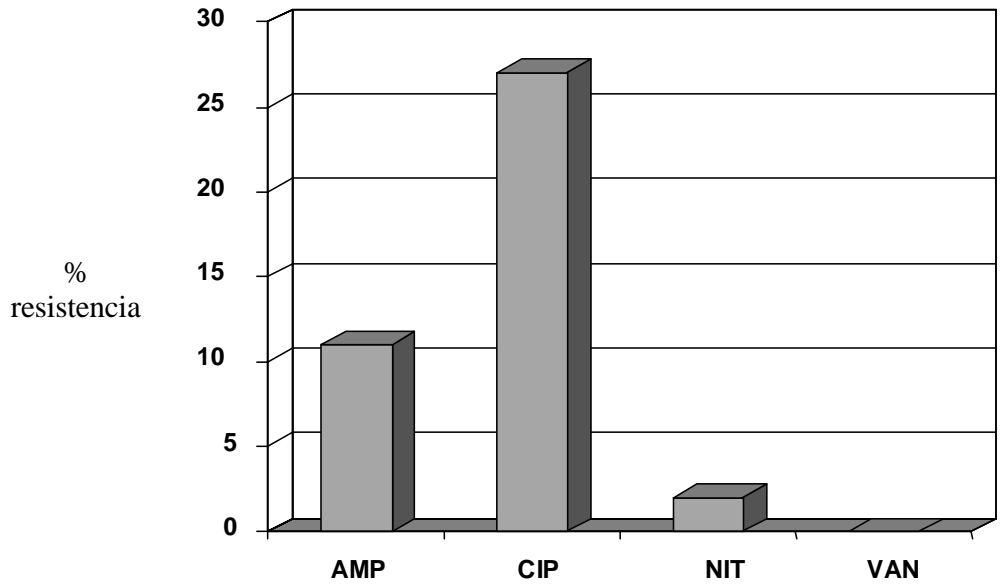

Gráfico 5. Resistencia de Enterococcus procedentes de infecciones del tracto urinario (n: 56). 


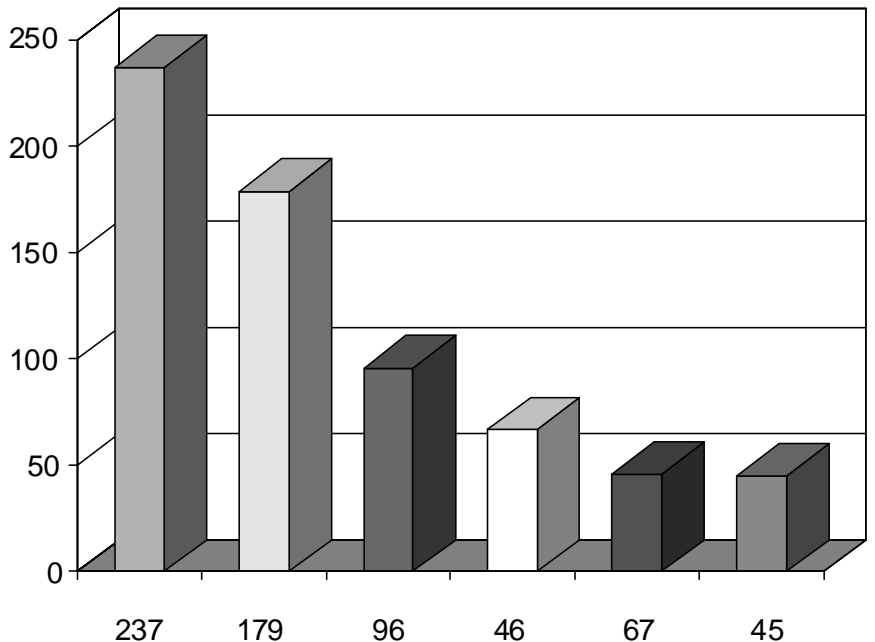

Staphylococcus aureus

$\square$ Escherichia coli

Klebsiella spp

S. pneumoniae

Pseudomonas spp

Acinetobacter $\mathrm{sp}$

Gráfico 6. Infecciones invasoras: Especies reportadas (n: 899).

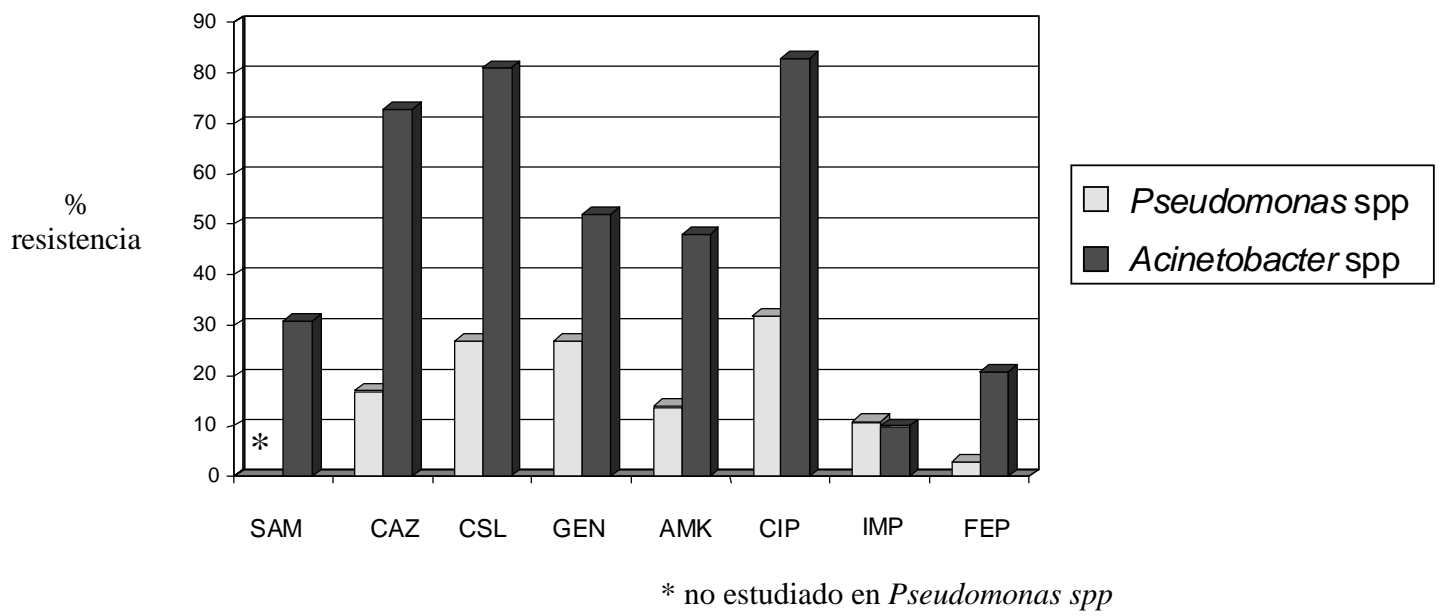

Gráfico 7. Resistencia de Pseudomonas sp (n: 45) y Acinetobacter sp (n: 45) procedentes de procesos invasores.

para la mayoría de los antimicrobianos estudiados (Gráfico 8).

De 1.109 cepas aisladas de infecciones de piel y tejidos blandos, $S$. aureus fue el agente más reportado (550 cepas), demostrando $21 \%$ de resistencia a cloxacilina, 11 y $25 \%$ de resistencia a ciprofloxacina y clindamicina respectivamente.

En infecciones entéricas fueron reportadas 207 cepas, de ellas 137 fueron especies de Shigella, las que demostraron elevado nivel de resistencia a ampicilina (80\%) y a cloranfenicol (32\%). Ciprofloxacina y furazolidona demostraron buena actividad frente a este enteropatógeno (Gráfico 9).
Se analizó la resistencia antimicrobiana de forma comparativa entre las cepas de $S$. aureus, Klebsiella spp y Pseudomonas spp, en que se reportó en formulario ad-hoc, si pertenecían a infecciones de la comunidad o eran de adquisición nosocomial. Se observó un aumento del nivel de resistencia, si ellas pertenecían al grupo de adquisición nosocomial (Gráficos 10, 11,12).

\section{DISCUSIÓN}

La resistencia bacteriana es detectada comúnmente durante el procedimiento microbiológico estándar para establecer la causa de la infección en el paciente y así elegir la mejor 


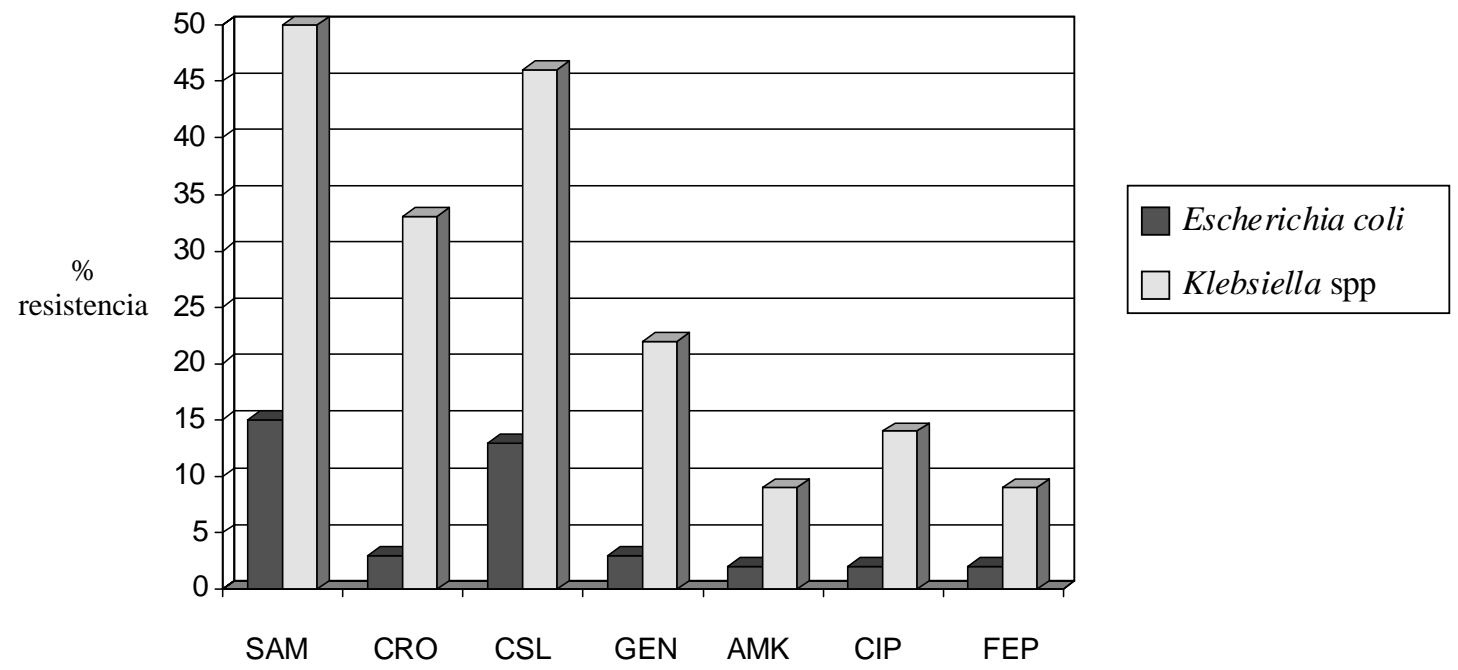

Gráfico 8. Resistencia de E. coli (n: 179) y Klebsiella spp (n: 96) aisladas de procesos invasores.

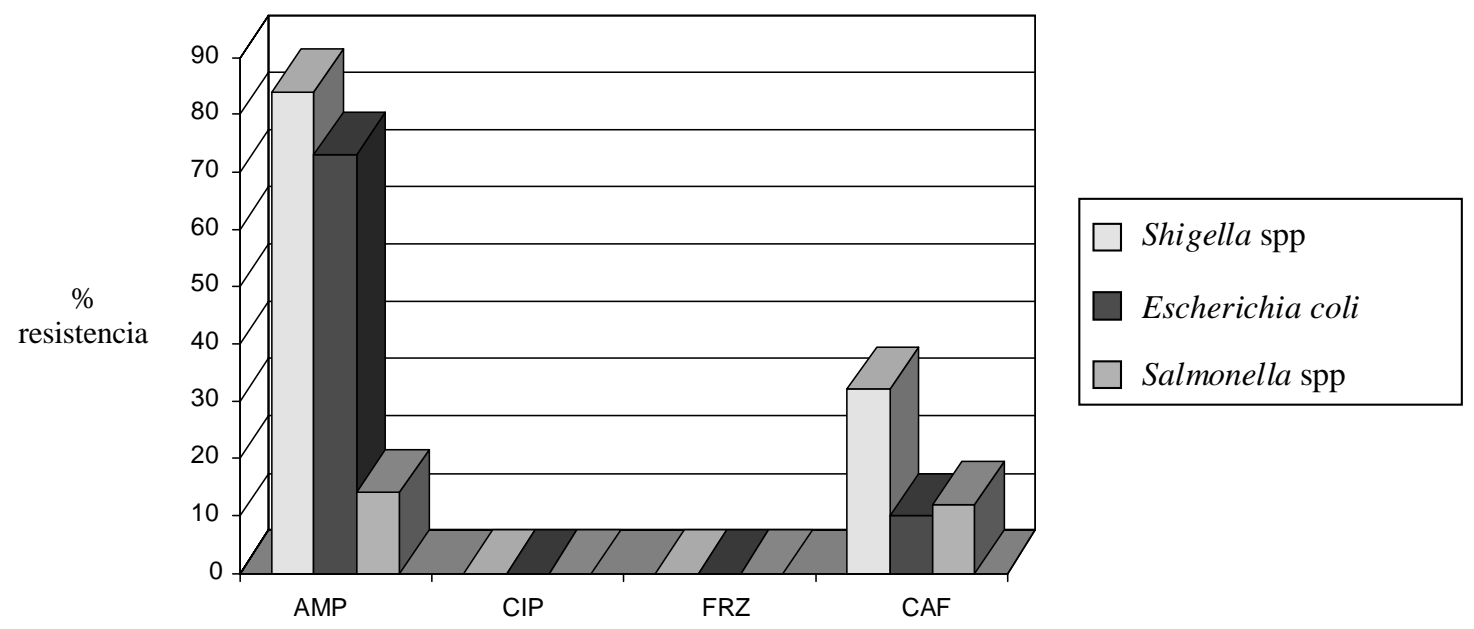

Gráfico 9. Resistencia de especies enteropatógenas Shigella spp (n: 137), Salmonella spp (n: 44), E. coli (n: 20).

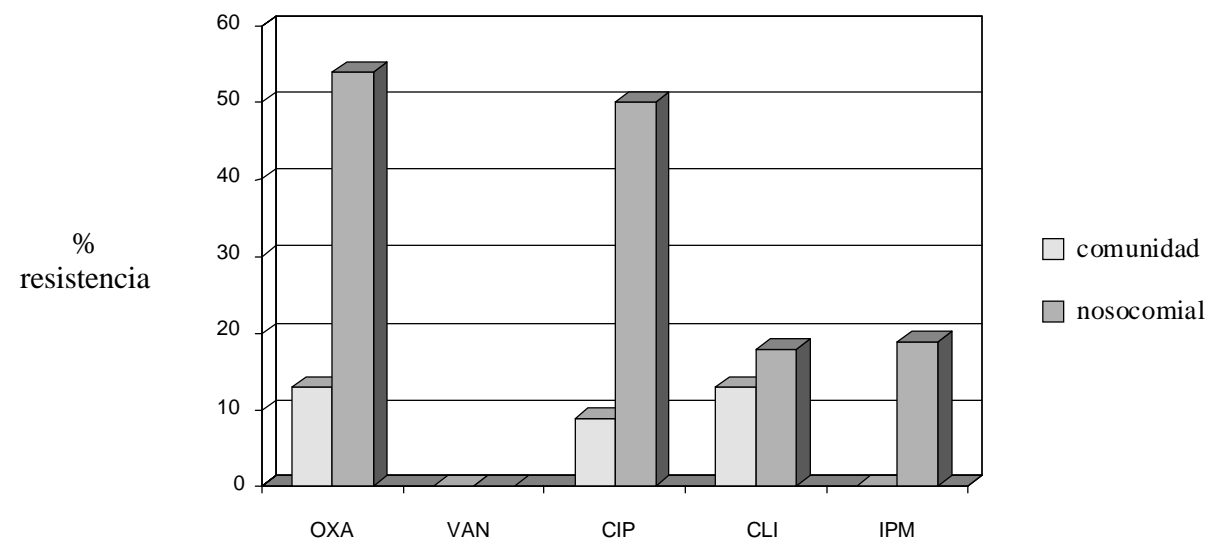

Gráfico 10. Resistencia de Staphylococcus aureus procedente de la comunidad (n: 241) y de origen nosocomial (n: 251).

S 146 


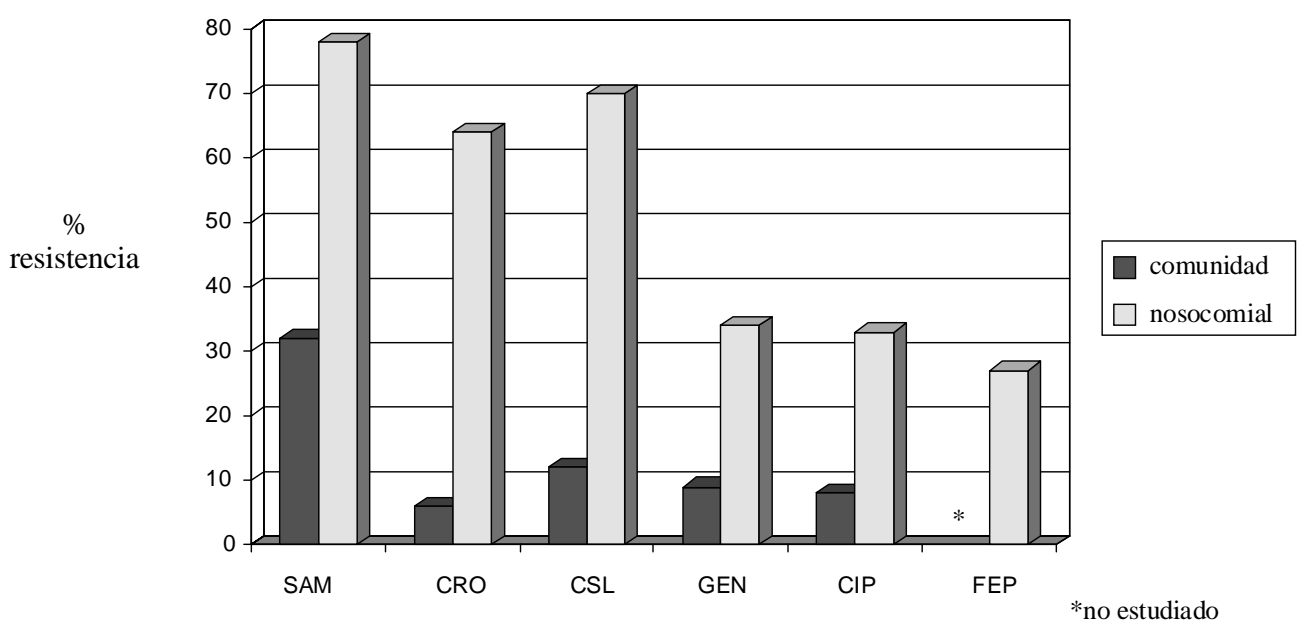

Gráfico 11. Resistencia de Klebsiella spp procedente de la comunidad (n: 122) y de origen nosocomial (n: 100).

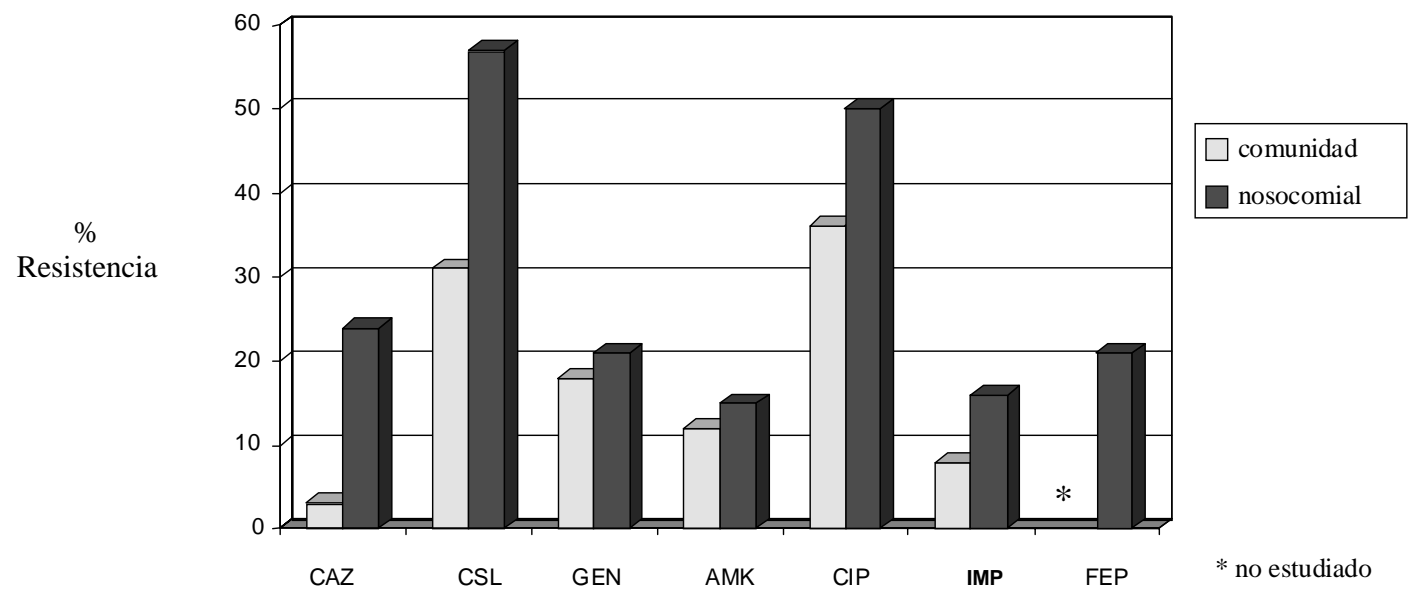

Gráfico 12. Resistencia de Pseudomonas sp procedente de la comunidad (n: 92) y de origen nosocomial (n: 82).

opción de tratamiento. Las infecciones por bacterias resistentes fallan en responder al tratamiento, resultando en una prolongada enfermedad, hospitalización y aumento del riesgo de muerte en infecciones graves.

Cuando las bacterias se muestran resistentes a los antimicrobianos de primera línea, el tratamiento debe cambiar a aquellos de segunda línea, que casi siempre son de mayor costo e incluso, algunos son administrados sólo por vía parenteral.

Esto hace fundamental contar con la información oportuna y al día de la epidemiología de la resistencia antimicrobiana, en el lugar donde se está desempeñando la labor médica, de modo de elegir el antibacteriano adecuado. Contar con una red de vigilancia permite obtener información institucional y nacional respecto de la resistencia en patógenos prevalentes, lo que ayudará en la toma de las decisiones.

En nuestro ámbito hospitalario, el aumento creciente de resistencia en bacilos Gram negativos a cefalosporinas de amplio espectro es un fenómeno nacional; Klebsiella spp se comporta como una bacteria altamente resistente en cualquiera localización.

Otro aspecto importante observado en los datos del PRONARES es la evolución creciente de la resistencia a cloxacilina de $S$. aureus, en el ámbito hospitalario su frecuencia fluctúa entre 30 y $50 \%$, muy diferente de lo observado en la comunidad en que $S$. aureus ha manteni- 
do valores inferiores a $20 \%$.

Entre los bacilos no fermentadores, Acinetobacter permanece como un agente patógeno problemático para tratar por su elevada resistencia, fenómeno que ha ido creciendo y que se hace presente también en otras regiones del país.

La reciente aparición de Enterococcus resistentes a vancomicina en nuestro medio, ha motivado un sistema de vigilancia ministerial de este patógeno. Entre las cepas reportadas al PRONARES, no hubo cepas resistentes; sin embargo, algunos hospitales de esta red han observado resistencia de Enterococcus a vancomicina.

Los agentes asociados a infecciones respiratorias bajas han sido reportados en pequeña cantidad, por lo que no se presentaron en esta revisión datos de resistencia.

Esperamos que los resultados de esta vigilancia ayuden a adecuar las pautas de tratamiento y cooperen en modificar conductas de riesgo que facilitan la inducción de resistencia, como el abuso en la prescripción de antimicrobianos y hospitalizaciones innecesarias.

\section{RESUMEN}

En el transcurso de los años hemos sido testigos de un creciente problema de resistencia antimicrobiana, fenómeno que involucra cada día mayor número de cepas, nuevas especies y nuevos mecanismos.

En noviembre de 1997 iniciamos una red de vigilancia de resistencia antimicrobiana PRONARES (Programa Nacional de Resistencia), en diferentes hospitales del país, que trabajando un protocolo común (20 cepas por síndrome clínico por mes) y utilizando un programa computacional WHONET (diseñado para vigilancia), nos permitiera detectar y monitorear el problema de la resistencia bacteriana en Chile.

Los resultados del primer semestre de este año reportan 5.251 cepas de diferentes síndromes clínicos. En ITU, Escherichia coli (1.088 cepas) demostró alta susceptibilidad a todos los antimicrobianos, Klebsiella (1.000 cepas) demostró un perfil de resistencia más elevado, en cepas de Enterococcus spp se observó $30 \%$ de resistencia a ciprofloxacina y $2 \%$ a nitrofurantoína.

Entre 899 cepas procedentes de infecciones invasoras, Staphylococcus aureus (555 cepas), mostró elevado perfil de resistencia a cloxacilina $40 \%$ superior $-40 \%$ - $(21 \%)$ al observado en cepas aisladas de piel y tejidos blandos (550). Shigella spp, (137 cepas) presentó $80 \%$ de resistencia a ampicilina y $32 \%$ a cloranfenicol; ciprofloxacina y furazolidona demostraron muy buena actividad in vitro frente a este enteropatógeno.

Al comparar cepas nosocomiales y de la comunidad, las primeras mostraron un perfil de mayor resistencia. Mantener una red nacional de vigilancia de resistencia se hace cada vez más necesario para orientar el uso adecuado de antibacterianos y evitar así que el fenómeno aumente.

Integrantes de PRONARES: Olivia Trucco, Valeria Prado, Claudia Durán, Maggie Vecchiola, Mónica Lafourcade, Patricia González, Carmen Mendoza, Verónica Quintana, Marcela San Martín, Alejandro Joyas, Berta Ossandón, Patricia Tapia, Carmen Cabezas, Cecilia Pefaur, Clara Mayorga, Raúl Ulloa, Geraldo Peralta, Ema Gaete, Mónica Grell, Sara Cisternas, Fermín Mendez y Gabriela Soto.

\section{BIBLIOGRAFÍA}

1.- COHEN M. Antimicrobial resistance prognosis for public health. Trends Microbiol 1994; 2: 422-5.

2.- MEDEIROS A. Evolution and dissemination of $\beta$-lactamases accelerated by generation of $\beta$-lactam antibiotics. Clin Infect Dis 1997; 24 (Suppl 1): 19-45.

3.- JONES R. Resistance patterns among nosocomial pathogens: trends over the past few years. Chest 2001; 119 (Suppl 2): 397-404.

4.- ROSSI A, TOKUMOTO M, GALAS M, SOLOAGA $\mathrm{R}$, CORSO A. y red nacional de laboratorios que participan en el programa WHONET. Vigilancia de la resistencia a los antibacterianos en Argentina. Programa WHONET, 1995-1996. Rev Panam Salud Pública 1999; 6 (4): 234-41.

5.- National Committee for Clinical Laboratory Standards (NCCLS). Performance standards for antimicrobial susceptibility testing. M100-S11. 2000.

Correspondencia a:

Olivia Trucco Aray

E-mail: olivia.trucco@aventis.com 